\title{
A geospatial enquiry into the nature of contemporary urbanisation in a medium-sized city of Mangaluru, India
}

Dhanaraj K ( $\square$ dhanarajk100@gmail.com )

Mangalore University https://orcid.org/0000-0002-9121-7314

Dasharatha P Angadi

Mangalore University

\section{Research Article}

Keywords: Medium-sized cities, Census towns, urban continuum, rural-urban transition, GIS, Mangaluru

Posted Date: May 18th, 2021

DOI: https://doi.org/10.21203/rs.3.rs-465484/v1

License: @ (1) This work is licensed under a Creative Commons Attribution 4.0 International License. Read Full License 


\section{Abstract}

The future of urban growth in India and the developing world is predicted to occur in small and medium-sized cities. Subtleties of such urbanisation need to be studied considering its implications for the future of urbanisation. The contemporary urbanisation is characterised by rural-urban transition and emerging small cities. An unprecedented increase in Census Towns (CTs) in India during the last decade has substantiated this fact. The growths of CTs and the medium-sized cities of India must be seen together. There is a dearth of studies that associates these two phenomena. Since the basic understanding of CTs and their dynamics is only based on studies of large cities, the current study attempts to bridge the gap in the literature through a case study of Mangaluru city. The study is conducted through a diversified method of remote sensing, GIS, statistical and spatial analysis. The results show up evidence of spatial expansion and rural-urban transition as emergent urbanisation at force in the region. The spatial proximity of CTs also adds to the spatiality of urban agglomeration in the region. This different form of locally driven urbanism of the contemporary period requires a different framework of participatory and technology-enabled smart planning for a sustainable future.

\section{Introduction}

Urbanisations are manifesting in new forms and in various complexities that intrigues academicians around the world. Particular forms of the vocabularies of urban growth that has caught the attention of urban geographers and planners in recent decades were rural-urban transition, peri-urbanisation and planetary urbanisation (Ford, 1999; Ravetz, Fertner, and Nielsen, 2013; Brenner and Schmid, 2013; Ruddick, Peake, Tanyildiz, and Patrick, 2017). The nature of these urban growths was such that they diverge substantially from the popularly held ideas and models of urban growth and are therefore highly complex.

The twenty-first century is often termed the urban century. Urbanisation is most popular and often the most contested emphasis of the environmental, economic, political, social and of course academic discussions of the current century. Today for the first time in human history more than half of the world population belongs to the urban background (United Nations, 2018; World Bank, 2020). But on the contrary, the idea of 'urban century' is sometimes ridiculed on grounds of limitations in defining urban and rural spaces and the prevalence of planetary urbanisation in contrast to the traditional confined settlements, in the current times (Brenner and Schmid, 2013).

Conventionally, urban growth, economic development and population concentration have been intense in particular centres for centuries around the world (Frick and Rodríguez-Pose, 2018). This agglomeration of urban growth has been proven beneficial for some countries and has been a burden to some others. However, growth beyond a certain threshold of such agglomeration can well be predicted to take place in the secondary or small cities of that nation (Mitra and Kumar, 2015; Pickett and Zhou, 2015; Agergaard, Tacoli, Steel, and Ørtenblad, 2019). Today these presumptions of urban growth were seen precisely manifesting in the smaller cities of developing countries.

The urbanisation in India has similarly experienced dramatic changes with investments in IT labour mobility in the late 80s and 90s (Mohan and Dasgupta, 2004; Tumbe, 2016; Kundu, 2007). A rapid increase in urban population is predicted in India in coming decades, and remarkably unlike the conventional Metropolis centric growth, the small cities with a population of less than a million are expected to host those urban populations 
(United Nations, 2018; World Bank, 2020). Another unique phenomenon of sub-urbanisation which is often generally expected to take place in the advanced stages of urban development has already been rampant in India (World Bank, 2013). World Bank, 2013 report on urban growth in India states sub-urbanisation in the periphery of major metropolitan cities as the signature Indian urbanisation. Unlike the popularly accepted concept of large scale migration driven urban growth of the west, the population in these urban centres have increased largely by the natural growth than migration. There is a fundamental change in India's urban growth from mega city-centric growth to regionally influenced and spatially diverse urban growth in recent times (Pradhan and Charan, 2013; Duijne and Nijman, 2019; Duijne, Choithani, and Pfeffer, 2020).

Census Tows (CTs), as they are called, have brought in a different dimension to the contemporary urban scenario of India. The census towns are defined as urban by the Census of India as an area with a minimum 5000 population, with a minimum population density of 400 persons per square Kilometre and at least $75 \%$ of male main working populations must be engaged in non-primary activities (Census of India, 2011). This definition was for the first time adopted during the census of 2001, during which there were 1362 census towns which has increased to 3894 during the 2011 census, an increase of 185\% (Census of India, 2001; Census of India, 2011). The census of 2011 in India has revealed a new trend that the urban growth in the country is no more centred on the big cities as was the case earlier; rather it is driven by the emergence of innumerable small towns across the country. The rapid increases in the number of Census Towns are held as a testimonial to it. They have shaped and influenced considerably the growth of small and medium towns, which is going to be the future centres of Indian urban growth.

Census towns are merely defined as urban areas but they are not governed by any urban body. In other words, they are only technically been recognised as urban. The urban growth of the $21^{\text {st }}$ century is often conspicuously marked by the emergence of copious growth in the peri-urban area (Ford, 1999). The general pattern of distribution of census towns in India shows that they are not seen distributed as stand-alone, rather they sprout out in a pattern certainly influenced by some common factors, and therefore form a larger cluster of urban areas in different parts of the country (Pradhan and Charan, 2013). In Kerala, of south-western India, for example, a huge concentration of census towns can be seen whereas on contrary in central and north-western India complete absence of census towns can be observed (Mitra and Kumar, 2015).

The study puts into perspective the circumstances of emerging medium-sized cities across India in general. The present study intends to recognise the spatial dynamics of locally driven, contemporary urbanisation in the context of rural-urban transition and rapid increase and the influences of CTs in Mangaluru taluk, a port town in southern India. The study area consists of Mangaluru urban agglomeration and the surrounding villages. The present study examines how the rural-urban transformation and the occurrence of census towns have contributed significantly to the growth of Mangaluru city in the western coastal plains of southern India. Mangaluru is an emerging medium-sized city, which has experienced rapid growth after the 1990s, can therefore be linked with the emergence of CTs. Furthermore, the contemporary forms of urban growth require a new integrated framework for an action plan that addresses sustainable development goals (Pickett and Zhou, 2015).

The study emphasises the nature and form of urban growth, the evolution of the city and the role of census towns. The work, employing the techniques of remote sensing, GIS and statistical methods was used to critically examine the rural-urban transition in Mangaluru. The methods broadly grouped as descriptive, spatial 
analytical techniques and statistical quantification using indices, in which physical aspects of built-up area, population dynamics, economic aspects and urban land consumption behaviour are studied. The study aims to analyse the contemporary urban growth scenario of rural-urban transition and the role of increasing census towns in the evolution of Mangaluru as an emerging medium-sized town. Furthermore intends to provide a functional understanding of the contemporary and future of Indian urbanisation and to suggest management measures.

\section{Literature review}

Contemporary urban transition is currently the popular topic of study in developing nations, for being unique. Urban transition refers to the shift from primarily rural to urban society (Farrell, 2018). Historically urban transition has followed certain defined stages around the world as captured by the ' $S$ ' shaped urban transition curve, describing the initial, accelerated and terminal stages of urban growth (Northam, 1979; Pacione, 2001). However, (Chen, 2012) highlights the limitations of the ' $S$ ' shaped curves in describing the urban transition in developing countries and the ' $\mathrm{J}$ ' shaped curves for developing countries. The phenomena of urban transition of rural settlements in-situ, in contrast to conventional migration driven urbanisation were identified in developing countries in recent times (Ginsburg, Koppel, and McGee, 1991; Zhu, QI, Shao, and HE, 2009; Tumbe, 2016; Samanta, 2018; Agergaard, Kirkegaard, and Birch-Thomsen, 2021). Further Zhu, Lin, Lin, and Chen, 2013 states that such urbanisation of in-situ origin is underestimated in the state statistical estimations of rural-urban transition. Literature survey reveals that small urban centres and non-metropolitan areas were professed to prosper in future (Rana and Krishan, 1981; Ganguly, 1997; Denis and Marius-Gnanou, 2011; Mulligan, 2013; World Bank, 2013). The urban transition of medium and small towns and their management is a new priority in India (Aijaz, 2021). Similarly, quite a lot has been said and researched about the rapid emergence of census towns in India in the context of planetary urbanisation which is being witnessed in the developing world (Verdini, 2017; Kumar and Shaw, 2020). Census towns have been the hot topic of numerous studies since the census of 2011 in India (Pradhan and Charan, 2013; Mitra and Kumar, 2015; Mukhopadhyay, Zérah, Samanta, and Maria, 2016; Duijne, 2019; Jain and Korzhenevych, 2020). These studies have recognised this phenomenon as an impending trend of Indian urbanisation, where small cities would make their way into the bigger urban landscape. Besides, these studies also identify the proximity of new census towns to larger cities. Nevertheless, the absence of case studies that examine this occurrence of census towns as a contributing factor in the growth of small and medium-sized cities in India is apparent in the literature (Saksena, et al., 2014; Sudhira, Ramachandra, and Jagadish, 2004; Swerts, 2017; Sahu, Das, and Bhuyan, 2019; Mauro, 2020). Recent studies making use of the advanced spatial analysis techniques of Geographic Information System (GIS) and remote sensing and spatial statistics in understanding the phenomena of rural-urban transition and planetary urbanisation can also be found in the literature (Shaw and Das, 2018; Jain and Korzhenevych, 2020). Remote sensing techniques enables to capture and generate the physical attributes of urban infrastructure using different bands of electromagnetic waves (Jensen and Cowen, 1999).GIS is a powerful computer-based spatial analysis tool in which spatial data analysis can be performed with spatial statistical models and computer codes (Cox, 1995; Lo and Yeung, 2007; Bhatta, 2010).

\section{Study area}

Mangaluru is a medium-sized coastal city in the southwestern part of Karnataka in southern India. Mangaluru is well known for its distinctive language, culture and multiplicity of customs. The region is also known for its 
unique ritualistic traditions, ancient spirit worship and cultural assortment. The history of urban settlements in the city dates to ancient antiquities (Dhanaraj and Angadi, 2020). This port city, known to have trade relationships with Arabia, China South-East Asia in ancient times and even travellers like Ptolemy of the far Greek land mentions this town in his work (Bhatt, 1969; Benjamin, 2017). Mangalore has been officially renamed Mangaluru in 2014 to do away with the colonial modulation.

The city locates in a narrow strip of land in the western coastal regions of India between the Western Ghats in the west and the Arabian Sea in the east (Fig. 1). The city lies in a relatively plain land and is encircled by River Gurupura and Netravathi in the north and south respectively. Demographically, the city can be considered as a part of a larger continuum of the region that spreads southward to the densely populated Kerala. This coastal strip has seen a huge leap in the number of new census towns, which has also resonated in Mangaluru. The region also resembles Kerala in a range of socio-economic indicators (Kudva, 2014). Mangaluru is a mediumsized town with a population of less than half a million. The urban agglomeration of Mangaluru consists of Mangaluru Corporation and its outgrowths, Mulki town panchayat, Kotekar town panchayath, Ullal city municipal council, and Someshwara town municipal council. Mangalore taluk contains a total of 22 census towns in 2011 which is an increase of $108 \%$ from the 2001 census year. The proximity of these CTs to the city of Mangaluru puts to conjecture, the proposition that the emergence of CTs and the development of the city are interlinked. The functional composition of the city reveals that the workers in the city are predominantly engaged in the tertiary and secondary sector than the primary sector.

Mangaluru is one of the fastest-growing medium-sized cities of India. Industries such as petrochemical processing, shipping, manufacturing, fishing, shipbuilding, tile factories etc. are prominent industries functioning in the city. The locational advantage of the city facilitates connectivity to the city with the rest of the world. Besides, the availability of land, natural and human resources makes this region highly conducive for industrial development and the concentration of economic activities. Most importantly, Mangaluru is an educational hub in the regions with students as far as Africa and south-east Asian countries. The effort to mould the city into a hub of soft service sector based on IT and education is also evident in the city. The recent surge in urban growth marked by transformations of village settlements into census towns in Mangaluru has drawn greater attention towards the importance of such medium-sized cities in the future urban development of the country.

\section{Data And Methods}

The study was presented based on the mixed methodology, in which remote sensing and GIS techniques were used to relate the process of urban growth and to visualise spatial development of the census towns and also to explore rural-urban transformation in peri-urban areas of Mangaluru city. Here the process of urban transformation in Mangaluru and its surrounding villages was carried out employing spatial analysis techniques. The study uses a mixed-method approach to study contemporary urban growth in the relatively small city of Mangaluru, with the help of geospatial data sets such as satellite images, boundary polygons, census data and field information.

In this study, initially, the demographic characteristics, spatial evolution and the distribution of the CTs in Mangaluru city were discussed and then the spatial analysis of built-up characteristics, built-up patches and rural-urban transition was investigated to comprehend contemporary urbanisation in the region and finally, 
statistical analysis has been carried out to examine the variations in land-use consumption in the city and its periphery.

\section{Data sources}

The data used in the study consisted of both spatial and non-spatial nature, which were collected from multiple sources. The spatial data comprises mainly satellite imageries and the administrative boundaries of city and villages etc. The satellite imageries were collected from Landsat, Resourcesat and Sentinel-2 satellites for the year 1972, 1990, 2000, 2011 and 2020 based on availability and periodicity (Table 1) while non-spatial data included demographic data, economic data and other census data derived from census handbooks of Dakshina Kannada district from the year 1961 to 2011 for 10 years interval published by the census of India. Software such as ArcGIS and ERDAS IMAGINE is used to analyse urbanisation in Mangaluru.

Table 1 Metadata of satellite images used in the study

\begin{tabular}{|lllll|}
\hline Mission & Sensor & Acquisition Date & Path/Row & Spatial resolutions \\
\hline Landsat 1 & MSS & $01-12-72$ & $156 / 051$ & $60 \mathrm{~m}$ \\
\hline Landsat 5 & TM & $04-03-1990$ & $145 / 051$ & $30 \mathrm{~m}$ \\
\hline Landsat 7 & ETM + & $20-12-00$ & $145 / 051$ & $30 \mathrm{~m}$ \\
\hline Resourcesat-1 & LISS III & $18-11-2011,23-11-2011$ & $(098 / 064,097 / 064)$ & $24 \mathrm{~m}$ \\
\hline Sentinel-2 & MSI & $07-01-20$ & T43PDQ & $10 \mathrm{~m}$ \\
\hline
\end{tabular}

Image classification, built-up extraction and accuracy assessment

The satellite image classification was performed to derive the urban built-up land of Mangaluru city and its periurban area. The images were initially subjected to image registration using the nearest neighbour resampling method (Aber, Marzolff, Ries, and Aber, 2019) to remove inaccuracies during overlaying of different images caused due to different spatial reference systems used by different image providing organizations. However, the satellite images used in the study though were having different spatial resolutions (Table 1) were not put to pixel resampling to prevent information loss. Then to extract built-up area from the satellite image, the maximum likelihood classifier algorithm was used to classify spectral signatures of land use features by supervised classification technique in ERDAS IMAGINE (Strahler, 1980; Lillesand, Kiefer, and Chipman, 2015). To measure the accuracy of these classified images more than 200 random points were selected from each image. Then the accuracy of the classified images was checked using Google earth images, toposheets and on-site data. The overall accuracy of the images was found to be $91.09 \%$ in $1972,94.21 \%$ in $1990,91.55 \%$ in 2000 , 90.13 in 2011 and 92.67 in 2020. The overall Kappa accuracy of the classified images was found to be 0.88 , 0.92, 0.89, 0.88 and 0.88 for the year 1972, 1990, 2000, 2011 and 2020 respectively, which were considered fairly good for scientific usages (Anderson, Hardy, Roach, and Witmer, 1976). These classified images were then reclassified into two binary classes as urban and non-urban for analysing the urban growth in Mangaluru city and its peri-urban area.

Interpretative analysis 
An analysis of the evolution of the city of Mangaluru and the emergence of census towns' proximity to the city was conducted using census data. The evolution and the changing dynamics of critical socio-economic and demographic factors of the Mangaluru taluk area were analysed to capture the rural-urban transition and the emergence of urban settlements in the region. The census data of the year 1991, 2001 and 2011 were considered for the study of census towns since the concept of CT first appeared in the 1991 census enumeration. The interpretation was performed on census data of statutory towns and census towns. The statutory towns consist of urban bodies of Mangaluru City Corporation, Town Municipal Councils and Town Panchayats. The trend in population growth, density, literacy, the proportion of people engaged in agriculture and the proportion of built-up were analysed using census data. A general account of the urbanisation process is also provided from referred materials and personal understanding.

\section{Spatial analysis}

The Spatio-temporal analysis of the dynamics of urbanisation in Mangaluru was carried out for the last 60 years. The emphasis was laid on the rural-urban transformation neighbouring the small city and also on the recent surge in the number of new CTs as a contributing factor of urban growth in the region. The villages and urban administrative boundaries within the taluk of Mangaluru from the year 1961 to 2011 are digitised from the administrative maps and the respective census data has been integrated with these spatial data using ArcGIS. Then these Shapefiles are used to spatially visualise the changing status of villages and urban bodies over time and the consumption of villages by the growing city, particularly over the rural tracks surrounding the city were studied.

Spatial analysis techniques such as, multiple concentric rings based urban density analysis and Kernel Density Estimate (KDE) are employed to capture the dynamics of built-up growth particularly to realise the rural-urban transition in the peri-urban area of Mangaluru. In multiple concentric ring analysis, a concentric circle of $1 \mathrm{~km}$ interval from the central business district has been drawn (Fig. 2) to cover the entire study area to analyse the distribution of built-up land (Dadras, Shafri, Ahmad, Pradhan, and Safarpour, 2015; Jiao, 2015; Dong, Jiao, Xu, Yang, and Liu, 2019). The density of the built-up area in each ring was calculated by dividing the total built-up area in a ring by its total area. While calculating the density, water bodies present in each circular ring were clipped from the area of each circular ring, since water bodies are unlikely to be transformed into the built-up area.

Then to demarcate urban area in Mangalore different ranges of built-up densities were considered. The built-up area densities threshold were used to delimit urban area into four parts as the urban core, inner core, sub-urban and fringe or peri-urban area based on the density threshold of $>60 \%, 40-60 \%, 20-40 \%$ and $<20 \%$ respectively. The range of density value for each urban division was categorised comparatively based on the existing highest and lowest values of urban density. The density of built-up area decreases consecutively from the dense urban core area to the urban fringe. Generally, urban core and inner core area are characterised by high density and the narrow band of built-up area whereas the suburban and fringe urban areas are characterised by a less dense, sparse and wide band of built-up area. The urban densities also reveal the form of urban area based on the above divisions. The ratio between the regions of the urban core, inner core, sub-urban and fringe or peri-urban area was also used to determine the form and nature of urban growth in the city. Then the boundaries of villages, CTs and towns were overlaid on these divisions of the urban area to spatially visualise the distribution of these administrative units and to contrast them with their status of built-up density. 
Finally, KDE was used to determine and contrast the distribution of the density of built-up patches in the main urban core area and the periphery. Kernel Density tool is an effective tool to spatially visualise the distribution and concentration of features around a neighbourhood (Smith, Goodchild, and Longley, 2018; Bonnier, Finné, and Weiberg, 2019; Yin, 2020). Higher the value of Kernel density, the higher the built-up patch distribution density and vice-versa. The tool helps to create a smooth circular surface around the built-up patch centroids and thus create a heat map of spatial concentration of features in an area. In the current study, kernel density of built-up patches for the year 1972, 1990, 2000, 2011 and 2020 was produced to visualise the shifting epicentres of newly grown built-up patches in the study area. The density map was prepared using the centroid points of built-up patches to capture the progression of increasing settlements concentration at the periphery over the years. The analysis was performed to understand the variations of settlement distribution in the centre and the periphery region of the city. The population field in the KDE tool in ArcMap was kept as none so that only the counts of built-up patches would be considered in the calculation.

\section{Statistical indices}

To understand the spatial expansion of the city into its periphery and to work out the consumption of new land by growing population, statistical indices such as Land Consumption rate (LCR) and Land Absorption Rate (LAC) were employed in the study. Land Consumption Rate (LCR) (Eq. 1)was used to estimate the compactness of the city growth which indicates the spatial expansion of the city and the Land Absorption Rate (Eq. 2) calculates consumption of urban land by increasing urban population (Sharma, Pandey, and Nathawat, 2012; Samuel and Atobatele, 2019). LCR and LAC are calculated using the following equation.

$\mathrm{LCR}=\mathrm{A} / \mathrm{P}$

Where, $\mathrm{A}$ is the extent of the built-up area of the city in hectares, $\mathrm{P}$ is the total population

$$
L A C=\frac{A_{2}-A_{1}}{P_{2}-P_{1}}
$$

Where, $A_{1}$ and $A_{2}$ are the extent of the built-up area of the city in hectares for the earlier and later years, and $P_{1}$ and $P_{2}$ are the population for the previous and later years, respectively. The low and high values of LCR indicate the high and low density of the built-up area respectively, while LAC values show the expansion of the built-up area spatially outward from the city core (Sharma, Pandey, and Nathawat, 2012). The LCR and LAC estimates of built-up for Mangaluru was calculated for the year 1972, 1990, 2000 and 2011 based on the availability of satellite images to extract built-up area and demographic data from census publications. The statistic was calculated individually for the main urban area and for the fringe area based on the above density-based classification to distinguish the growth rate in two distinct regions. The statistics of LCR and LAC demonstrates the nature of urban growth in the region.

To analyse the spatial pattern and the dynamics of peri-urban area settlement patches, spatial metrics such as the number of built-up patches, patch area, mean patch area, and Largest Patch Index (LPI), which is the proportion of the largest patch to the landscape area, is used. Spatial metrics are indices that quantify physical characteristics of a patch, between patches and its relationship with the surrounding landscape (Turner and Gardner, 2015; Dutta and Das, 2019). Spatial indices were calculated for the built-up patches in the peri-urban area for the year 1972, 1990, 2000, 2011 and 2020. These metrics reveal the changes in the composition, 
structure and spatial pattern of settlements in the peri-urban area over the years. Matrices such as LPI and MPS would indicate the aggregation of built-up area, and the NP would specify the fragmentation of the landscape. The LPI value increases when built-up patches become more aggregated and wise versa.

\section{Results And Discussions}

\section{The Spatio-temporal scenario of urban growth in Mangaluru}

Mapping of the urban growth in Mangaluru involves quantification and visualisation of the built-up area derived from the classified satellite images from 1972 to 2020. In Mangaluru, the built-up area has seen an increase of more than 500 per cent during a period of 48years (Table 2). Annually on average, about 236 ha of built-up area was gained in Mangaluru and the surrounding area. The built-up accretion and urban growth in Mangaluru have occurred radially from the historic urban centre. The semi-circular or fan-shaped growth of urban area seems to occupy either side of the transportation network at initial years and then got intensified by filling up the intermediate vacant spaces (Fig. 3). The settlement concentration can be visible at three zones of the city, the one developed around the older city and the other two came up around the new Special Economic Zones (SEZs) and educational and medical institutes in the outskirts of the city. The growth of the city of Mangaluru over the years has taken place in the northern and southern part, besides the growth in the core urban area surrounded by the river Netravathi and Gurupura. Moreover, intensification of settlements over the years can also be observed in the peri-urban or fringe areas of the city (Fig. 4).

Table 2 Area of built-up in Hectares in Mangaluru from 1972 to 2020

\begin{tabular}{|llllll|}
\hline Year & 1972 & 1990 & 2000 & 2011 & 2020 \\
\hline Built-up (Ha) & 2100.24 & 2524.77 & 4287.6 & 6169.053 & 13429.53 \\
\hline
\end{tabular}

Furthermore, rural settlements though were not intruded much by the expanding urban infrastructure of the city since the 1970s; however, the effects of urban growth were obvious in later decades. The rural hinterlands except along the highways and specially allocated economic zones have witnessed built-up fragmentation by the natural increase in population. Thus it could be postulated that the steady growth of built-up land is more obvious in the city and the surrounding area, while rural-urban transition at the periphery is dominated by lowdensity built-up land.

The total population of the Mangaluru Corporation, comprising of City Corporation (MCC) and its Out Growths (OGs) accounts for 4.9 lakh according to the 2011 census and the urban agglomeration consisting of MCC+OGs and one TP and TMC each. The city contains a total population of just more than half a million. Besides, the population in census towns within the taluk of Mangaluru accounts for approximately 1.84 in 2011, which was roughly, double the population of census towns in 2000.

\section{The emergence of census towns in Mangaluru}

The analysis of the distribution of population growth rate in the villages and urban areas of Mangalore taluk from 1961 to 2011 (Fig. 5a - f) reveals that the decadal growth rate ranging between $50 \%$ to > 50\% is prevailing 
throughout the study area. It can also be noticed from Fig. $5 f$ that during the period of last 50 years the areas which have experienced a population growth rate of more than $100 \%$ is located in the southern part of the taluk bordering the city. Similarly, some patches of high-density growth were also seen in the eastern and northern part of the taluk. The area where the population growth rate has more than doubled matches precisely with the locations of new emergent CTs. Thus, substantiating the fact that the proximity to the city influences the population growth in the region and also interlinked with the emergence of CTs per se. The intensive growth rate in the southern and eastern part of the taluk indicates a strong pull towards the south and southeast as opposed towards the north-eastern part where the presence of industries and agricultural land acts as a deterrent for population settlements.

The emergence of CTs in Mangaluru taluk in such large numbers particularly from 2001 to 2011 is evident, during which the number of new CTs has increased by $120 \%$ as can be observed from Table 3 . The continuous downfall in the total density of populations in CTs indicates increasing CTs number, compensating new land area. Interestingly the increase in population during 2001 to 2011 was considerably higher in CTs than STs in Mangaluru. The higher growth rate of the population in CTs suggests immigration from the neighbouring rural hinterland of the taluk. The comparisons of literacy rate show that the difference between the two is minimal and there is a rapid increase in the literacy rate of the CTs. The trivial presence of people in agricultural activities and the continuous decrease in their share of the total working population in STs and CTs are apparent. While there is a rapid decline of agricultural activity in STs, whereas, only a marginal decline can be observed in the CTs, suggesting the prevalence of a rural lifestyle. The increase in built-up proportion in the CTs was only marginal during 1991, 2001 and 2011. This minimal increase points towards lack of infrastructural development activities as opposed in the statutory towns of Mangaluru.

The declining density of population, diminishing primary activities and at the same time marginal increase of built-up area in the CTs specifies the ingestion of large villages by CTs. And also the abandoning of agricultural lands due to shifting economic activities was causing the conversion of farmland built-up land. The increase in population and changes in economic activities are largely locally driven, and therefore these STs and CTs together contribute to the advent of urbanisation in the region and the emergence of Mangaluru as a mediumsized city. To further understand these rural-urban transitions and to visualise the status of urbanisation in the region, elaborate spatial analysis and statistical methods were applied.

Table 3 Variances amongst demographic features of STs and CTs of Mangalore taluk for the year 1991, 2001 and 2011 


\begin{tabular}{|lllllll|}
\hline Census Year & 1991 & & 2001 & & 2011 & \\
\hline Urban Status & STs & NMCTs & STs & CTs & STs & CTs \\
\hline Number & 3 & 7 & 3 & 10 & 3 & 22 \\
\hline Population & 351186 & 159280 & 482546 & 92820 & 560015 & 184604 \\
\hline Change in Population & - & - & 37.40 & -41.73 & 16.05 & 98.88 \\
\hline Density & 4284.30 & 3561.85 & 3754.88 & 1546.40 & 3834.74 & 1203.21 \\
\hline \% of Literate & 85.60 & 81.26 & 88.20 & 86.40 & 93.00 & 89.66 \\
\hline \% of Primary activity & 15.05 & 6.78 & 3.10 & 6.48 & 1.43 & 4.67 \\
\hline Built-up density (\%) & 16.62 & 4.82 & 23.23 & 6.26 & 25.19 & 6.87 \\
\hline Built-up & 13.62 & 2.16 & 29.85 & 3.76 & 36.79 & 10.55 \\
\hline Area (Sq.km) & 81.97 & 44.72 & 128.51 & 60.02 & 146.04 & 153.43 \\
\hline
\end{tabular}

Spatial analysis of urban processes in Mangaluru

The spatial differentiation of the built-up area and its temporal dynamics in the core urban area and the rural hinterland are juxtaposed. Then, the spatial distribution of CTs and the changing status of villages are also visualised. Initially, to demarcate the urban and rural areas, built-up area density was calculated based on concentric multiple ring buffer of $1 \mathrm{~km}$ from the city centre (Fig. 2). As it can be seen from Fig. 6 that there is a sharp increase in the curves of built-up area density in the central part of the city, which continuously decreases in the direction of the periphery. The density curves of the built-up area were created for the year 1972, 1990, 2000, 2011 and 2020. The curves show the cross-sectional profile of the city's growth, in which horizontal growth of the city is captured. From 1972 to 2000 the gain in the built-up area is minimal; however, during 2011 and 2020 a leap in the growth of the built-up area can be seen. The negative growths in certain places are however caused by the errors introduced during image classification and caused by the obscuring of built-up by vegetation. The steep and gently declining curve from the centre of the city points to a compact and narrow core and inner core whereas, the flat curves indicates a wider sub-urban and fringe area at Mangaluru. Therefore the form of built-up implies a centralised compact form of growth which implies that the urban growth is in a relatively young stage at Mangaluru city. However, expanding urban core area can be recognised from the curves (Fig. 6) as time progresses.

The built-up proportions based on the density of $>60 \%, 40-60 \%, 20-40 \%$ and $<20 \%$, was used to demarcate the urban forms as the urban core, inner core, sub-urban and fringe or peri-urban areas respectively (Fig. 7a - e). The demarcation was used to distinguish between urban and rural area. From the Fig. $7 \mathrm{a}$ - e the spatial and temporal expansion of dense urban core and the inner core of the city can be seen. However, the relatively small and narrow proportion of the core areas of the city makes it compact, and also at the same time sprawling. The spatial expansion of sub-urban area and simultaneously the reduction in the peri-urban stretch is also apparent at the temporal scale. 
The Kernel density estimation was used to distinguish the spatial and temporal variation of built-up patches across the urban and rural landscape of Mangalore taluk. The analysis was carried out using layers of urban density demarcation boundary at the backdrop of Kernel density, where core, inner core, sub-urban was grouped as an urban area and the peri-urban area was considered as the rural region. The variations of built-up patch density in these two regions were contrasted. The kernel density variations in Fig. 8 a - e shows shifting hotspots of built-up patches density from urban core areas to peripheral rural region with year. A departure of the built-up hotspot from the high-density urban core area of the city to suburban and peri-urban areas can be seen in the later periods. This is due to the increasing new built-up patches in the sub-urban and peri-urban area away from the centre of the city with the progress of years. In 1972 the density of built-up patches was concentrated near the downtown Mangaluru city and along the coastal stretch in the north-south direction. The regions near Surathkal, Mulki in the north and Ullal, Thokkotu in the south of the city were the primary hotspots of built-up density. In the year 2011 and 2020, the patches were exhibiting a scattered distribution, in which the built-up patch with the highest density value was seen at the periphery, suggesting increased settlement dispersion and urbanisation of rural villages (Fig. $8 \mathrm{~d}$ and e). At the same time, the kernel density values were low or zero at the centre of the city and along the coastal stretch during this period. Besides, the concentration of built-up patches was seen in the north, south-east and eastern part, which were earlier characterised by sparsely distributed lowdensity rural settlements. To sum up, the kernel density distribution of built-up patches shows an increasing trend of rural-urban transition at force in Mangaluru during the 1972 to 2020 period. In the periphery of Mangaluru, where low-density rural settlements were prominent, which can be expected to intensify in terms of built-up area and consequently in the number of population.

\section{Visualising spatial distribution of census towns}

According to the 2011 census, there were a total of 22 census towns in Mangalore taluk of which 12 CTs were newly added which gives a growth rate of $120 \%$. The distributions of CTs are seen concentrated in specific areas explicitly bordering Mangaluru City Corporation (Fig. 9). A majority of the CTs were seen in the southern and the eastern part of the taluk. On the contrary, there are no CTs in the north and north-eastern part of the taluk, which is also isolated from the urban influence. An isolated, Talipady CT near Mulki town, where a national and state highway passes through, can be seen sprang out without any major influence of urban attraction.

The distribution of CTs, Mangaluru city, major transportation network and the built-up area was overlaid in Fig. 9a-b. In Fig. 9b the built-up area of 2011 is juxtaposed against the locations of CTs shows that the CTs are lacking in infrastructure growth. The spatial pattern of CTs distribution shows that the CTs were located in proximity to urban area. The new CTs in 2011 were emerging within the close range of the old CTs and therefore presumed that the spatial proximity with each other, sharing some common boundary is a distinctive feature of the CTs in the region. A closer examination of Fig. 9a reveals that the emergence of CTs in such proximity and clusters were facilitated by well-connected transportation links in the area. These factors drive us to deduce that the future locations of CTs would be incessant to the current CTs and would be directed by the presence or absence of major highways. The rural-urban transition is occurring in a phased manner from the proximity of the city and thus contributes to the emergence of an agglomeration of urban governing bodies which eventually cause the emergence of the medium-sized city of Mangaluru. 
To understand the Spatio-temporal dynamics of built-up patches and to quantify their spatial arrangement in the rural periphery the spatial metrics of built-up patches are calculated. This helps to capture rural-urban transition quantitatively. The peri-urban area is demarcated based on built-up density calculation. There is an obvious increase in the number of patches from 1972 to 2020 . The growth in patch number was sluggish till 2000 and which come to be more pronounced during the 2000 to 2011 period (Table 4). The decrease in the number of patches during 2020 was due to the smaller peri-urban area due to the expansion of the core and sub-urban area of Mangaluru city. The increase in the patch area is steady from $2.60 \%$ to total available land area in 1972 to 8.93 in 2020. This indicates the greater diversification of rural settlements and slower accumulation of infrastructure development in the periphery of the city. The mean patch size, on the one hand, shows a decreasing trend, whereas the largest patch area, in contrast, shows an increasing trend from 1972 to 2020. This hints out at a small local aggregation of rural settlements and consequently contributes to the emergence of small towns in the rural periphery. The constant increase in the largest patch index can also indicate the transition of rural settlement types to urban and the aggregation shows changing economic activities in the rural hinterland of Mangalore taluk.

Table 4 Peripheral built-up patch metrics of Mangaluru city for the year 1972, 1990, 2000, 2011 and 2020

\begin{tabular}{|llllll|}
\hline Year & $\mathbf{1 9 7 2}$ & $\mathbf{1 9 9 0}$ & $\mathbf{2 0 0 0}$ & $\mathbf{2 0 1 1}$ & $\mathbf{2 0 2 0}$ \\
\hline Patch number & 751 & 4784 & 7189 & 46252 & 20983 \\
\hline Patch area (Ha) & 1401.29 & 1662.30 & 2655.58 & 3630.03 & 1845.04 \\
\hline \% PA to area of landscape & 2.60 & 3.09 & 5.25 & 7.87 & 8.93 \\
\hline Area of landscape & 53875.00 & 53875.00 & 50593.56 & 46134.78 & 20672.11 \\
\hline Largest patch Index & 0.078 & 0.196 & 0.197 & 0.933 & 2.477 \\
\hline Mean patch size & 1.87 & 0.35 & 0.37 & 0.08 & 0.09 \\
\hline S.D of patch areas & 3.57 & 1.97 & 2.01 & 2.88 & 3.58 \\
\hline
\end{tabular}

$\angle C R$ and $L A C$

Land consumption rate and land absorption coefficient have been estimated separately for the urban and rural village areas of Mangalore taluk. The LCR value was relatively higher in the urban area than the rural areas in the year 1972, the same was seen declining in the year 1990, and then again the LCR value increases for the year 2000 and 2011 (Table 5). A similar trend can also be observed in LCR values in rural areas of Mangalore taluk from 1972 to 2011. In general land, consumption is increasing with the increase in population, with obvious differences between urban and rural areas. The increasing LCR values indicate a trend of intensive urban growth within the city and also the development of low-density settlements in the periphery of the city. The increase in land consumption in the periphery corresponding to the increase in the urban area shows the interconnection between the two entities and thus the prevalence of the rural-urban transition at force is evident in the region. 
The coefficient of land absorption for the period 1972 to 2011 in the urban area of Mangaluru varies from 0.0015 to 0.0085 . However, the LAC in the rural area decreases to negative coefficient value for the period from the year 1972 to 2000 and there was a slight increase of LAC from 2000 to 2011 period (Table 5). The increasing trend of LAC value in the urban area suggests the spatial expansion of the city of Mangalore and the movement of the people further towards the outskirts of the city. In other words, the acquisition of new land at the outskirts of the city limits can be caused by the high rate of increasing population. The trend of changes in LAC values at the periphery of the city was distinctly different, where decreased LAC value from 1972 to 2000 indicates intense growth of settlements, but from 2000 to 2011 the settlements experienced extensive and outspread growth into vacant lands of rural area. The increase in rural population and acquiring of abandoned agricultural fields for the construction activities can also be a factor instigating the increased LAC values in the recent period. Thus the results of LCR and LAC analysis shows increasing developmental activities in the rural areas than urban areas of Mangalore taluk and also brings to light the active rural-urban transition in Mangaluru.

Table 5 LCR and LAC differences between the urban and rural area of Mangalore from 1972 to 2011

\begin{tabular}{|c|c|c|c|}
\hline Year & & Urban & Rural fringe \\
\hline \multirow[t]{4}{*}{1972} & Built-up & 944.28 & 1155.96 \\
\hline & Population & 35754 & 281533 \\
\hline & LCR & 0.0264 & 0.0041 \\
\hline & LAC & - & - \\
\hline \multirow[t]{4}{*}{1990} & Built-up & 1306.17 & 1218.6 \\
\hline & Population & 281161 & 399192 \\
\hline & LCR & 0.0046 & 0.0031 \\
\hline & LAC & 0.0015 & 0.0005 \\
\hline \multirow[t]{4}{*}{2000} & Built-up & 2931.39 & 1356.21 \\
\hline & Population & 449460 & 337346 \\
\hline & LCR & 0.0065 & 0.0040 \\
\hline & LAC & 0.0097 & -0.0022 \\
\hline \multirow[t]{4}{*}{2011} & Built-up & 4090.99 & 2078.060443 \\
\hline & Population & 586170 & 304438 \\
\hline & LCR & 0.0070 & 0.0068 \\
\hline & LAC & 0.0085 & -0.0219 \\
\hline
\end{tabular}

\section{Conclusions}


The study was presented as an overview of contemporary urbanisation in a medium-sized town of Mangaluru, in southern India, based on its spatial, physical quantitative and selected socio-economic characteristics. The current study attempted to enquire the Spatio-temporal dynamics of rural-urban transition in the context of the increasing number of Census Towns as a key factor in the emergent urbanisation of Mangaluru. The present study reveals an association between the increasing CTs and the rapid evolution of the city of Mangaluru. It has been confirmed from the present study that the expansion of the city of Mangaluru was through incorporating the surrounding villages and statutory towns and also the interwoven connection and reliance between the rural and urban centre were the essence of the contemporary urbanisation in Mangaluru. The ruralurban transition was found prominent in the region, forming an urban continuum facilitated by the regional advantages and access to forefront technology and global telecommunication. A large proportion of the working population is increasingly being migrating towards Middle Eastern countries, making a significant move from the agricultural sector to secondary and tertiary sectors particularly in rural parts of Mangaluru. The Kernel density analysis has also shown rapid spatial expansion and accretion of built-up area away from the urban centre. The LCR and LAC values highlight that the periphery of the city is becoming hotspots of urban growth than the main urban core.

It may be contended that the proximity of CTs to the urban area makes it favourable to be incorporated in the future urban agglomeration of Mangaluru. The emergence of Mangaluru city and the CTs act as complementary to each other. The status of contemporary urbanisation reveals a trend in which physical and socio-economic features of the urban and rural area at the same time. This could be taken as a sign of a new form of urbanism taking place in the country, which in the case of Mangaluru we have validation of rural-urban transformation evident from the increased built-up area densities, shifting economic activities, spatial expansion and urban continuum. Therefore the emergence of CTs and medium-sized cities must be read together since the future of Indian urban growth is expected in such cities. Most significantly the governments should recognise these transforming rural settlements as urban by giving urban status and providing mechanisms to deal with urban growth and thus the uncontrolled future urban growth in India can be managed sustainably (Samanta, 2018; Jain and Korzhenevych, 2020; Aijaz, 2021).

Further understanding of rural-urban transition, urban continuum, emerging census towns and medium-sized towns necessitates additional research; involving finer details of a larger scale data (which is lacking in India) for the comprehensive understanding of the phenomena. However, urban growth in such cities must be sustainable and well managed. To ensure the sustainability of urban growth beyond the traditional urban confines of a city and also for their future growth a new framework of participatory and smart urban planning must be designed and adopted in such medium-sized cities.

\section{Declarations}

Acknowledgement: I would like to express my sincere thanks to the University Grants Commission, Govt. of India, for the financial assistance through the $\mathrm{PhD}$ research fellowship. Gratitude is also due to Ms Sandipta Das for the valued assistance during the fieldwork. Support of friends, colleagues and family is also gratefully acknowledged.

Conflicts of Interests: Author declares no conflicts of interest with respect to the research, authorship and publication of this work. 
Funding: The research work is funded by the University Grants Commission, Ministry of Human Resource Development, Govt. of India, (No.F.15-9(JULY 2016)/2016(NET)).

Conflicts of Interests: Author declares no conflicts of interest with respect to the research, authorship and publication of this work.

\section{References}

Aber, J. S., Marzolff, I., Ries, J. B., and Aber, S. E. (2019). Digital Image Processing and Analysis. In Small-Format Aerial Photography and UAS Imagery: Principles, Techniques, and Geoscience Applications (Second Edition ed., pp. 191-221). Academic Press. Retrieved from https://doi.org/10.1016/B978-0-12-812942-5.00011-2

Agergaard, J., Kirkegaard, S., \& Birch-Thomsen, T. (2021). Between Village and Town: Small-Town Urbanism in Sub-Saharan Africa. Sustainability, 13(3), 1417. Retrieved from https://doi.org/10.3390/su13031417

Agergaard, J., Tacoli, C., Steel, G., and Ørtenblad, S. B. (2019). Revisiting Rural-Urban Transformations and Small Town Development in Sub-Saharan Africa. The European Journal of Development Research volume, 31, 2-11. doi: $10.1057 / \mathrm{s} 41287-018-0182-z$

Aijaz, R. (2021, January 4). Managing India's urban transition in 2021. Retrieved from Observer Research Foundation: https://www.orfonline.org/expert-speak/managing-india-urban-transition-2021/

Anderson, J. R., Hardy, E. E., Roach, J. T., and Witmer, R. E. (1976). A Land Use and Land Cover Classification System for Use with Remote Sensor Data. USGS professional paper 964, 138- 145. Retrieved from http://pbcgis.com/raster/anderson.pdf

Benjamin, S. (2017). Multilayered Urbanisation of the South Canara Territory. In E. Denis, and M.-H. Zérah, Subaltern Urbanisation An Introduction to the Dynamics of Ordinary Towns (pp. 199-233). New Delhi: Springer Nature. Retrieved from https://doi.org/10.1007/978-81-322-3616-0_8

Bhatt, P. G. (1969). Antiquities of South Kanara. Udupi: Prabhakara Press. Retrieved from http://203.200.22.249:8080/bitstream/123456789/12240/1/Antiquites_of_south_Kanara.pdf

Bhatta, B. (2010). Analysis of Urban Growth and Sprawl from Remote Sensing Data. Heidelberg: Springer.

Bonnier, A., Finné, M., and Weiberg, E. (2019). Examining Land-Use through GIS-Based Kernel Density Estimation: A Re-Evaluation of Legacy Data from the Berbati-Limnes Survey. Journal of Field Archaeology, 44(2), 70-83. Retrieved from https://doi.org/10.1080/00934690.2019.157048

Brenner, N., and Schmid, C. (2013). The 'Urban Age' in Question. International Journal of Urban and Regional Research, 38(3), 731-755. doi: 10.1111/1468-2427.12115

Census of India. (2001). List of Towns and Their Population. Retrieved from Census of India: https://www.censusindia.gov.in/towns/town.aspx

Census of India. (2011). Census of India 2011. Retrieved from Some concepts and Definitions: https://censusindia.gov.in/2011-prov-results/paper2/data_files/kerala/13-concept-34.pdf 
Chen, Y.-g. (2012). On the Urbanization Curves: Types, Stages, and Research Methods. SCIENTIA GEOGRAPHICA SINICA, 32(1), 12-17. Retrieved from https://doi.org/10.13249/j.cnki.sgs.2012.01.12

Cox, A. B. (1995). An overview to geographic information systems. The Journal of Academic Librarianship, 237249. Retrieved from https://doi.org/10.1016/0099-1333(95)90003-9

Dadras, M., Shafri, H. Z., Ahmad, N., Pradhan, B., and Safarpour, S. (2015). Spatio-temporal analysis of urban growth from remote sensing data in Bandar Abbas city, Iran. The Egyptian Journal of Remote Sensing and Space Sciences, 35-52. Retrieved from http://dx.doi.org/10.1016/j.ejrs.2015.03.005

Denis, E., \& Marius-Gnanou, e. (2011). Toward a better appraisal of urbanization in India: A fresh look at the landscape of morphological agglomerates. CyberGeo: European Journal of Geography. Retrieved from https://doi.org/10.4000/cybergeo.24798

Dhanaraj, K., and Angadi, D. P. (2020). A GIS based interpretation of the historical evolution of urban settlements in Mangalore City, India. Spatial Information Research, 1-15. doi:10.1007/s41324-020-00363-5

Dong, T., Jiao, L., Xu, G., Yang, L., and Liu, J. (2019). Towards sustainability? Analyzing changing urban form patterns in the United States, Europe, and China. Science of the Total Environment, 632-643. doi:

10.1016/j.scitotenv.2019.03.269

Duijne, R. J. (2019). Why India's urbanization is hidden: Observations from "rural" Bihar. World Development, 123. doi: 10.1016/j.worlddev.2019.104610

Duijne, R. J., and Nijman, J. (2019). India's Emergent Urban Formations. Annals of the American Association of Geographers, 109(6), 1978-1998. doi:10.1080/24694452.2019.1587285

Duijne, R. J., Choithani, C., and Pfeffer, K. (2020). New urban geographies of West Bengal, East India. Journal of Maps, 16(1), 172-183. doi:10.1080/17445647.2020.1819899

Dutta, I., and Das, A. (2019). Application of geo-spatial indices for detection of growth dynamics and forms of expansion in English Bazar Urban Agglomeration, West Bengal. Journal of Urban Management, 8(2), $288-302$. doi: 10.1016/j.jum.2019.03.007

Farrell, K. (2018). Rapid Urbanization: An Inquiry into the Nature and Causes of the Urban Transition in Developing Countries. Stockholm, Sweden: KTH Royal Institute of Technology. Retrieved from https://www.divaportal.org/smash/get/diva2:1257531/FULLTEXT01.pdf

Ford, T. (1999). Understanding Population Growth in the Peri-Urban Region. INTERNATIONAL JOURNAL OF POPULATION GEOGRAPHY, 5, 297-311.

Frick, S., and Rodríguez-Pose, A. (2018, February 14). Urban concentration and economic growth. Retrieved from https://voxeu.org/article/urban-concentration-and-economic-growth

Ganguly, R. (1997). Integrated Development of Small and Medium Towns in India. In K. Y. Chatterji M., Regional Science in Developing Countries (pp. 196-211). London: Palgrave Macmillan. Retrieved from https://doi.org/10.1007/978-1-349-25459-0_14

Page $17 / 28$ 
Ginsburg, N., Koppel, B., \& McGee, T. G. (1991). The Extended Metropolis: Settlement Transition in Asia. Honolulu: University of Hawaii Press.

Jain, M., and Korzhenevych, A. (2020). Urbanisation as the rise of census towns in India: An outcome of traditional master planning? Cities, 99. doi:10.1016/j.cities.2020.102627

Jensen, J. R., \& Cowen, D. C. (1999). Remote Sensing of Urban/Suburban Infrastructure and Socio-Economic Attributes. Photogrammetric Engineering \& Remote Sensing, 65(5), 611-622. Retrieved from https://www.asprs.org/wp-content/uploads/pers/99journal/may/1999_may_611-622.pdf

Jiao, L. (2015). Urban land density function: A new method to characterize urban expansion. Landscape and Urban Planning, 139, 26-39. doi:10.1016/j.landurbplan.2015.02.017

Kudva, N. (2014). Planning Mangalore Garbage Collection in a Small Indian City. In G. Shatkin, Contesting the Indian City Global Visions and the Politics of the Local (pp. 265-). West Sussex: John Wiley and Sons, Ltd.

Kumar, A., \& Shaw, R. (2020). Transforming rural light and dark under planetary urbanisation: comparing ordinary countrysides in India and the UK. Transactions of the Institute of British Geographers, 45(1), $155-167$. Retrieved from https://doi.org/10.1111/tran.12342

Kundu, A. (2007). Migration and Urbanisation in India in the Context of Poverty Alleviation. International Conference and Workshop on Policy Perspectives on Growth, Economic Structures and Poverty Reduction (pp. 3-9). Beijing, China: India infrastructure report. Retrieved from http://networkideas.org/ideasact/jun07/Beijing_Conference_07/Amitabh_Kundu.pdf

Lillesand, T. M., Kiefer, R. W., and Chipman, J. W. (2015). Remote Sensing and Image Interpretation (7 ed.). Westford: JohnWiley and Sons, Inc.

Lo, C. P., \& Yeung, A. K. (2007). Concepta and Techniques of Geographic Information Systems. New Jersey: Pearson Prentice Hall. Retrieved from https://doi.org/10.1080/1365881031000111173

Mauro, G. (2020). Rural-Urban Transition of Hanoi (Vietnam): Using Landsat Imagery to Map Its Recent PeriUrbanization. ISPRS Int. J. Geo-Inf., 9(11), 669. Retrieved from https://doi.org/10.3390/ijgi9110669

Mitra, A., and Kumar, R. (2015). New Patterns in Indian Urbanization: Emergence of Census Towns. Environment and Urbanization Asia, 6(1), 18-27. doi:10.1177/0975425315583755

Mohan, R., and Dasgupta, S. (2004). Urban Development in India in the Twenty First Century: Policies for Accelerating Urban Growth. Working Paper. Stanford Centre for International Development.

Mukhopadhyay, P., Zérah, M.-H., Samanta, G., and Maria, A. (2016). Understanding India's Urban Frontier: What Is behind the Emergence of Census Towns. Policy Research Working Paper 7923: World Bank Social, Urban, Rural and Resilience Global Practice Group. Retrieved from https://ssrn.com/abstract=2887778

Mulligan, G. F. (2013). The future of non-metropolitan areas. Regional Science: Policy and Practice, 5(2), 219224. Retrieved from https://doi.org/10.1111/rsp3.12005 
Northam, R. M. (1979). Urban Geography. New York: John Wiley \& Sons.

Pacione, M. (2001). URBAN GEOGRAPHY: A GLOBAL PERSPECTIVE. London, New York: Routledge Taylor \& Francis Group.

Pickett, S. T., and Zhou, W. (2015). Global urbanization as a shifting context for applying ecological science toward the sustainable city. Ecosystem Health and Sustainability, 1(1), 1-15. doi:10.1890/EHS14-0014.1

Pradhan, and Charan, K. (2013). Unacknowledged Urbanisation: The NewCensus Towns of India. Economic and Political Weekly, 48(36), 43-51. Retrieved from https://mpra.ub.uni-muenchen.de/41035/

Rana, P., \& Krishan, G. (1981). Growth of medium sized towns in India. GeoJournal, 5, 33-39. https://doi.org/10.1007/BF00185241

Ravetz, J., Fertner, C., and Nielsen, h. S. (2013). The Dynamics of Peri-Urbanization. In P. S. Nilsson K., Peri-urban futures: Scenarios and models for land use change in Europe (pp. 13-44). Berlin, Heidelberg: Springer. doi:10.1007/978-3-642-30529-0_2

Ruddick, S., Peake, L., Tanyildiz, G.”., and Patrick, D. (2017). Planetary urbanization: An urban theory for our time? Environment and Planning D: Society and Space, 36(3), 1-18. doi:10.1177/0263775817721489

Sahu, M., Das, K. C., \& Bhuyan, B. (2019). Role of Census Towns in Rising Urbanisation of India (Vol. LI). Retrieved from

https://www.researchgate.net/publication/340645628_Role_of_Census_Towns_in_Rising_Urbanisation_of_India

Saksena, S., Fox, J., Spencer, J., Castrence, M., DiGregorio, M., Epprecht, M., . . Vien, T. D. (2014). Classifying and mapping the urban transition in Vietnam. Applied Geography, 50, 80-89. Retrieved from https://doi.org/10.1016/j.apgeog.2014.02.010

Samanta, G. (2018). Beyond Metropolitan Shadow: Growth And Governance Of Small Towns In Eastern India. Jindal Journal of Public Policy, 3(1), 51-68. Retrieved from https://jgu.edu.in/jsgp/wpcontent/uploads/beyond_metropolitan_shadow.pdf

Samuel, K. J., and Atobatele, R. E. (2019). Land use/cover change and urban sustainability in a medium-sized city. International Journal of Sustainable Society, 11(1), 13-28. doi:10.1504/IJSSOC.2019.101961

Sharma, L., Pandey, P. C., and Nathawat, M. S. (2012). Assessment of land consumption rate with urban dynamics change using geospatial techniques. Journal of Land Use Science, 7(2), 135-148. doi:

10.1080/1747423X.2010.537790

Shaw, R., \& Das, A. (2018). Identifying peri-urban growth in small and medium towns using GIS and remote sensing technique: A case study of English Bazar Urban Agglomeration, West Bengal, India. The Egyptian Journal of Remote Sensing and Space Science, 21(2), 159-172. Retrieved from https://doi.org/10.1016/j.ejrs.2017.01.002

Smith, M. J., Goodchild, M. F., and Longley, P. A. (2018). Density, kernels and occupancy. In M. J. Smith, M. F. Goodchild, and P. A. Longley, Geospatial AnalysisA Comprehensive Guide to PrinciplesTechniques and Software 
Tools (pp. 172-190). London. Retrieved from http://www.spatialanalysisonline.com/

Strahler, A. H. (1980). The Use of Prior Probabilities in Maximum Likelihood Classification of Remotely Sensed Data. Remote Sensing Of Environment, 135-163.

Sudhira, H., Ramachandra, T., \& Jagadish, K. (2004). Urban sprawl: metrics, dynamics and modelling using GIS. International Journal of Applied Earth Observation and Geoinformation, 29-39.

doi:doi:10.1016/j.jag.2003.08.002

Swerts, E. (2017). The Substantial Share of Small Towns in India's System of Cities. In E. Denis, \& M.-H. Zérah, Subaltern Urbanisation in India An Introduction to the Dynamics of Ordinary Towns (pp. 67-89). New Delhi: Springer Nature. doi: 10.1007/978-81-322-3616-0_3

Tumbe, C. (2016). Urbanization, Demographic Transition and the Growth of Cities in India, 1870-2020. International Growth Center. Retrieved from https://www.theigc.org/wp-content/uploads/2016/11/Tumbe-2016Working-paper.pdf

Turner, M. G., and Gardner, R. H. (2015). Landscape Ecology in Theory and Practice: Pattern and Process (2nd ed.). New York, London: Springer. doi:10.1007/978-1-4939-2794-4

United Nations. (2018, May 16). United Nations. Retrieved February 19, 2020, from Department of Economic and Social Affairs: https://www.un.org/development/desa/en/news/population/2018-revision-of-worldurbanization-prospects.html

Verdini, G. (2017). Planetary Urbanisation and the Built Heritage from a Non-Western Perspective: The Question of 'How' We Should Protect the Past. Built Heritage, 73-82. Retrieved from https://built-

heritage.springeropen.com/track/pdf/10.1186/BF03545678.pdf

World Bank. (2013, October 21). Beyond the City Limits: Report Finds Rapid Suburban Growth in India, Potential for Sustainable Cities to Reduce Poverty. Retrieved from The World Bank:

https://www.worldbank.org/en/news/feature/2013/10/21/india-urbanization-report-beyond-sustainable-cities

World Bank. (2013). Urbanization beyond Municipal BoundariesNurturing Metropolitan Economies and Connecting Peri-Urban Areas in India. Washington DC: World Bank.

World Bank. (2020, April 20). Urban Development. Retrieved 08 21, 2020, from The world bank: https://www.worldbank.org/en/topic/urbandevelopment/overview

Yin, P. (2020). Kernels and Density Estimation. The Geographic Information Science and Technology Body of Knowledge. Retrieved from https://doi.org/10.22224/gistbok/2020.1.12

Zhu, Y., Lin, M., Lin, L., \& Chen, J. (2013). The Extent of In Situ Urbanisation in China's County Areas: The Case of Fujian Province. China Perspectives, 43-52. doi:10.4000/chinaperspectives.6263

Zhu, Y., Qi, X., Shao, H., \& HE, K. (2009). The Evolution Of China's In Situurbanization and Its Planning And Environmental Implications: Case Studies From Quanzhou Municipality. In A. A. Rahman, A. Barbieri, J. C. Fotso, \& Y. Zhu, Urban Population-environment Dynamics in the Developing World: Case Studies and Lessons Learned 
(pp. 213-245). Paris: Committee for International Cooperation in Natural Research in Demography. Retrieved from https://www.populationenvironmentresearch.org/workshops.jsp\#W2007

\section{Figures}
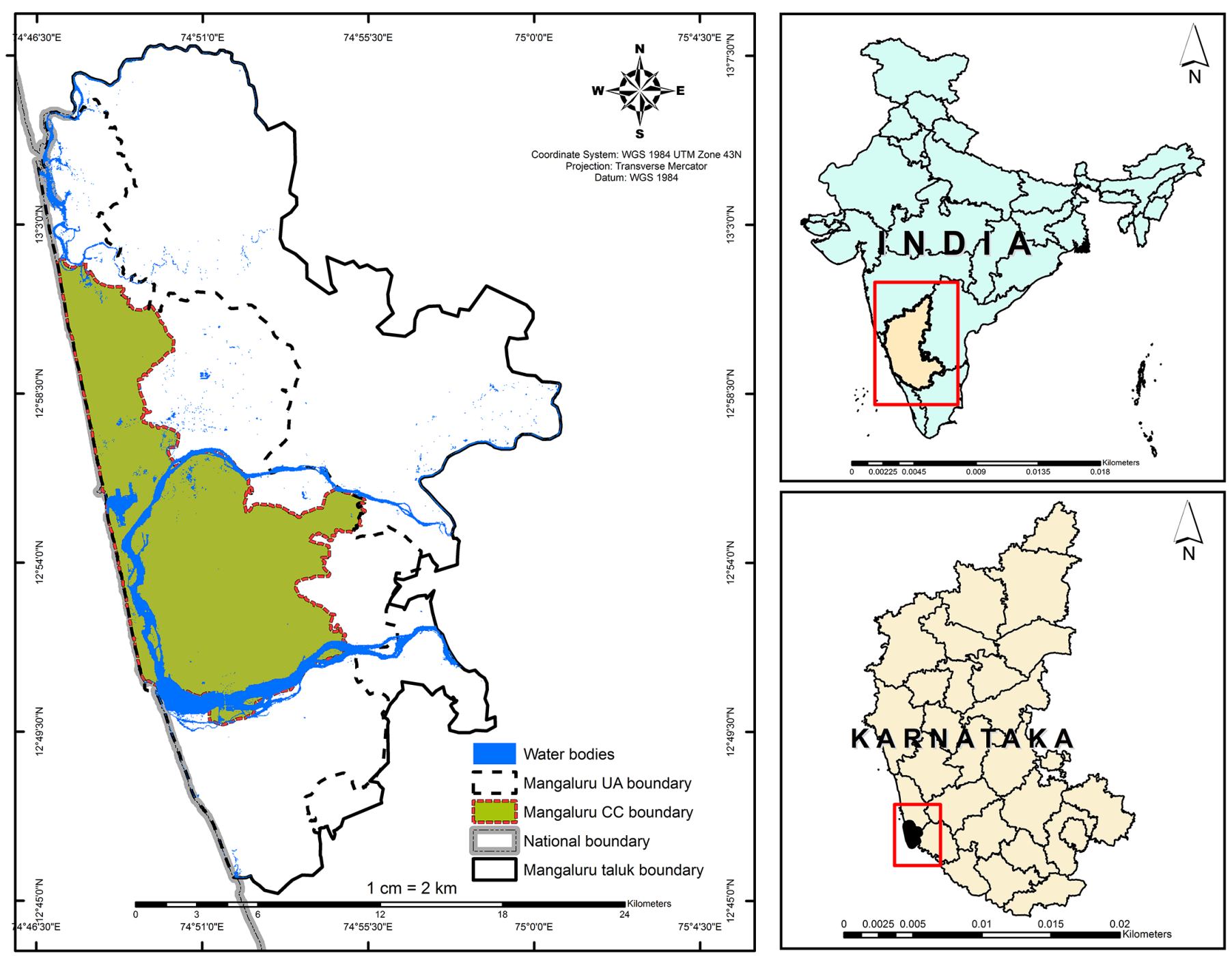

Figure 1

Location of the study area. Note: The designations employed and the presentation of the material on this map do not imply the expression of any opinion whatsoever on the part of Research Square concerning the legal status of any country, territory, city or area or of its authorities, or concerning the delimitation of its frontiers or boundaries. This map has been provided by the authors. 


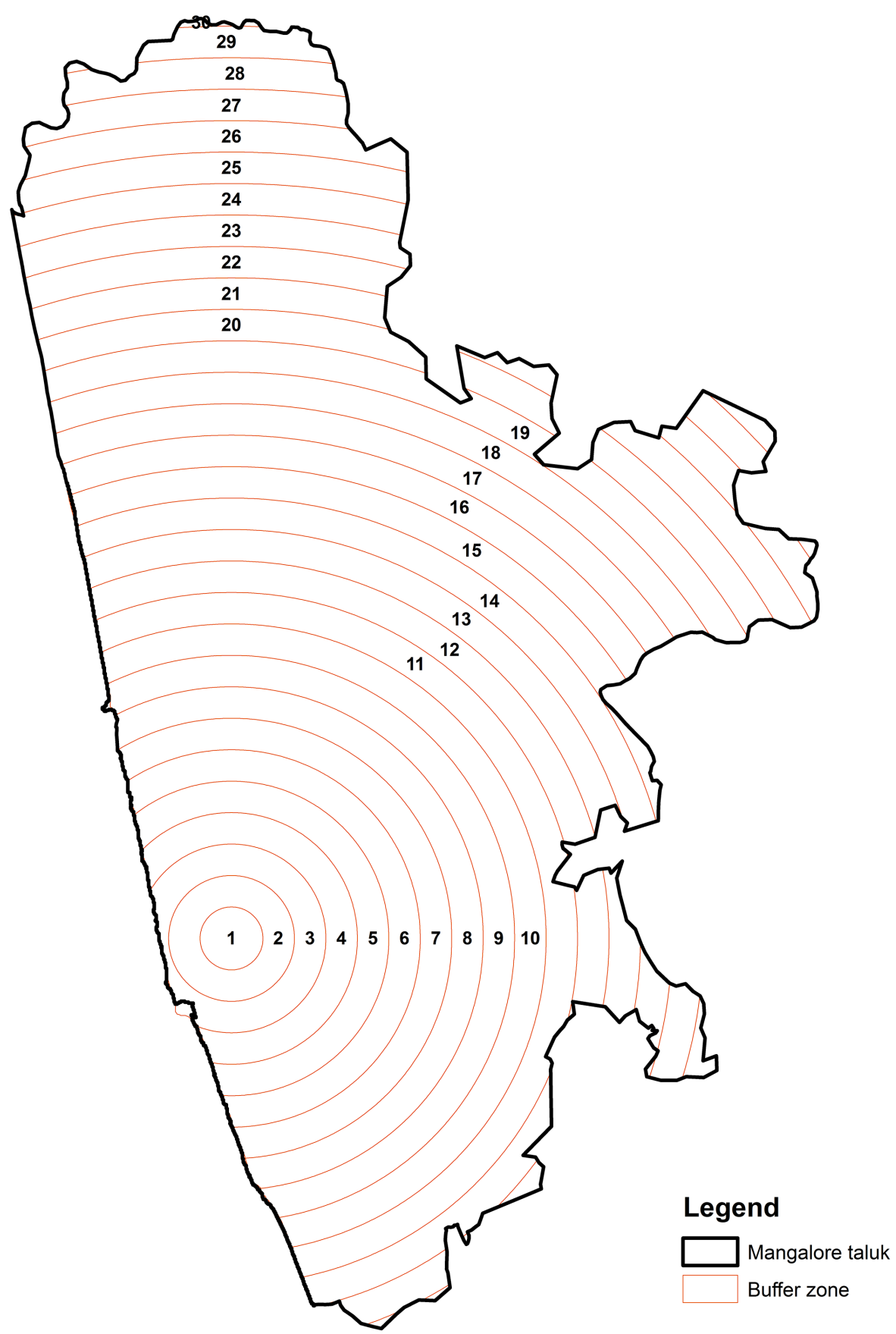

Figure 2

Concentric multiple ring buffer of $1 \mathrm{~km}$ from the centre of Mangaluru city 

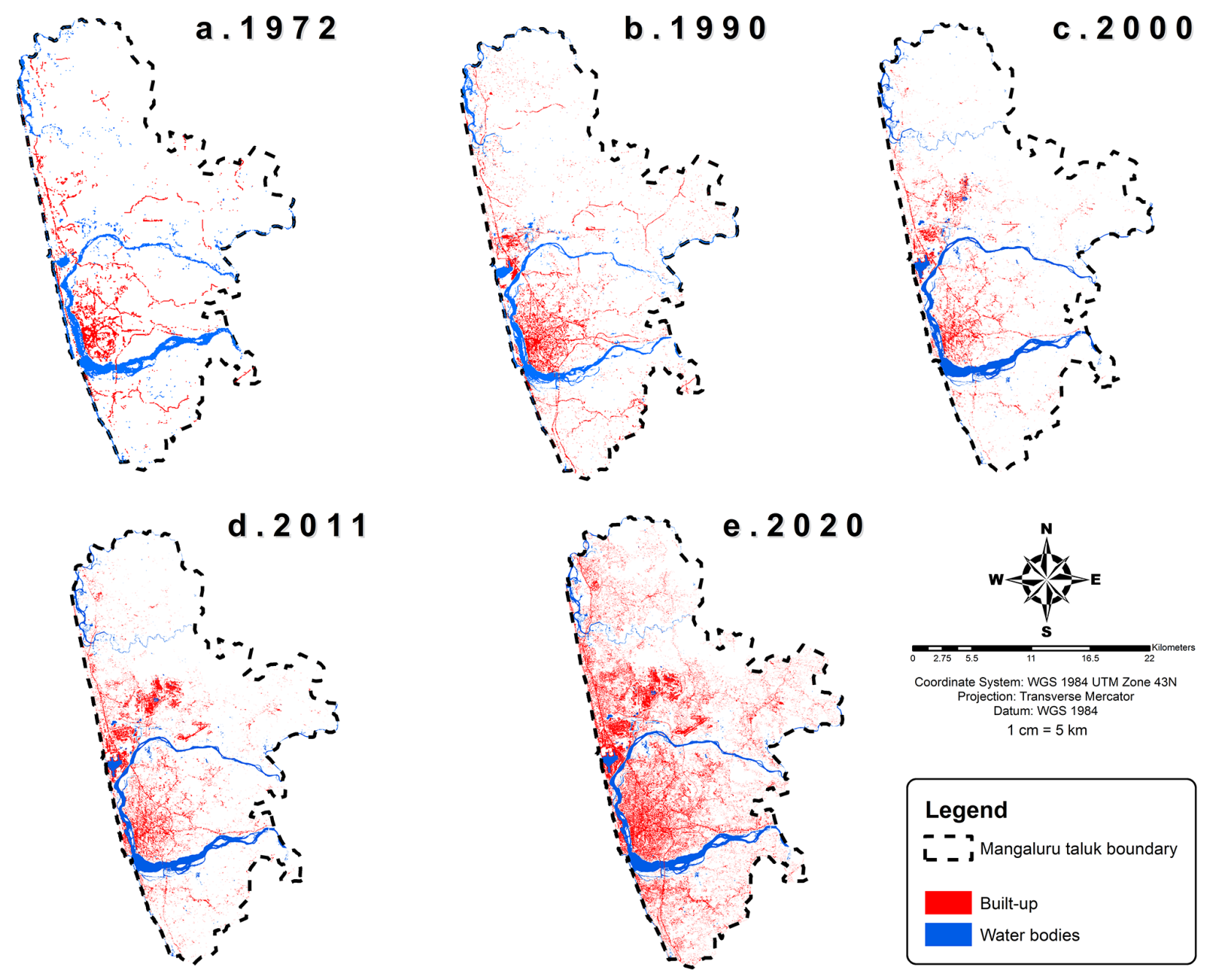

Legend

L - I Mangaluru taluk boundary

Built-up

Water bodies

Figure 3

Spatio-temporal expansion of the built-up area in Mangaluru from 1972 to 2020 


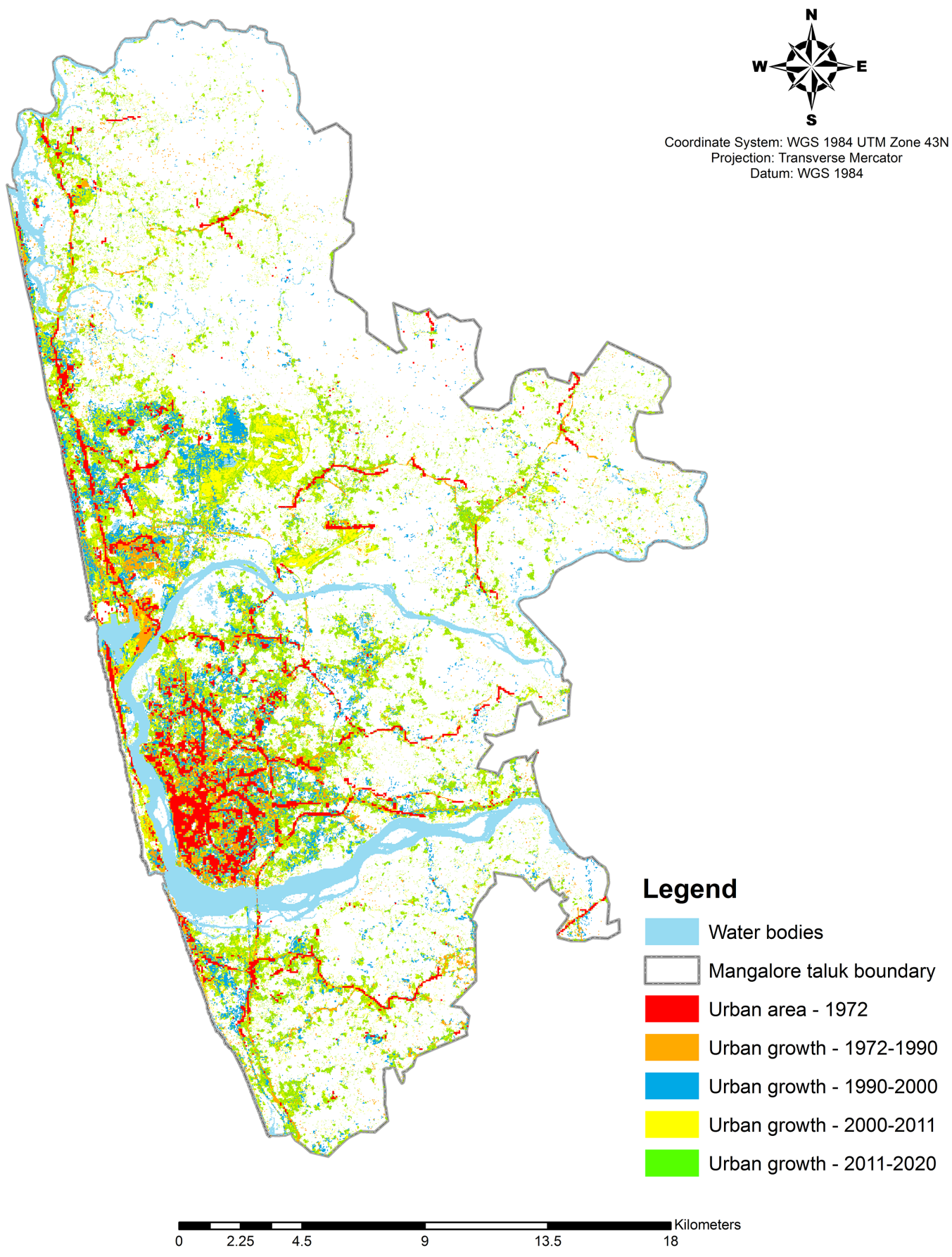

\section{Figure 4}

Spatial overlay of urban growth in Mangaluru from 1972 to 2020 

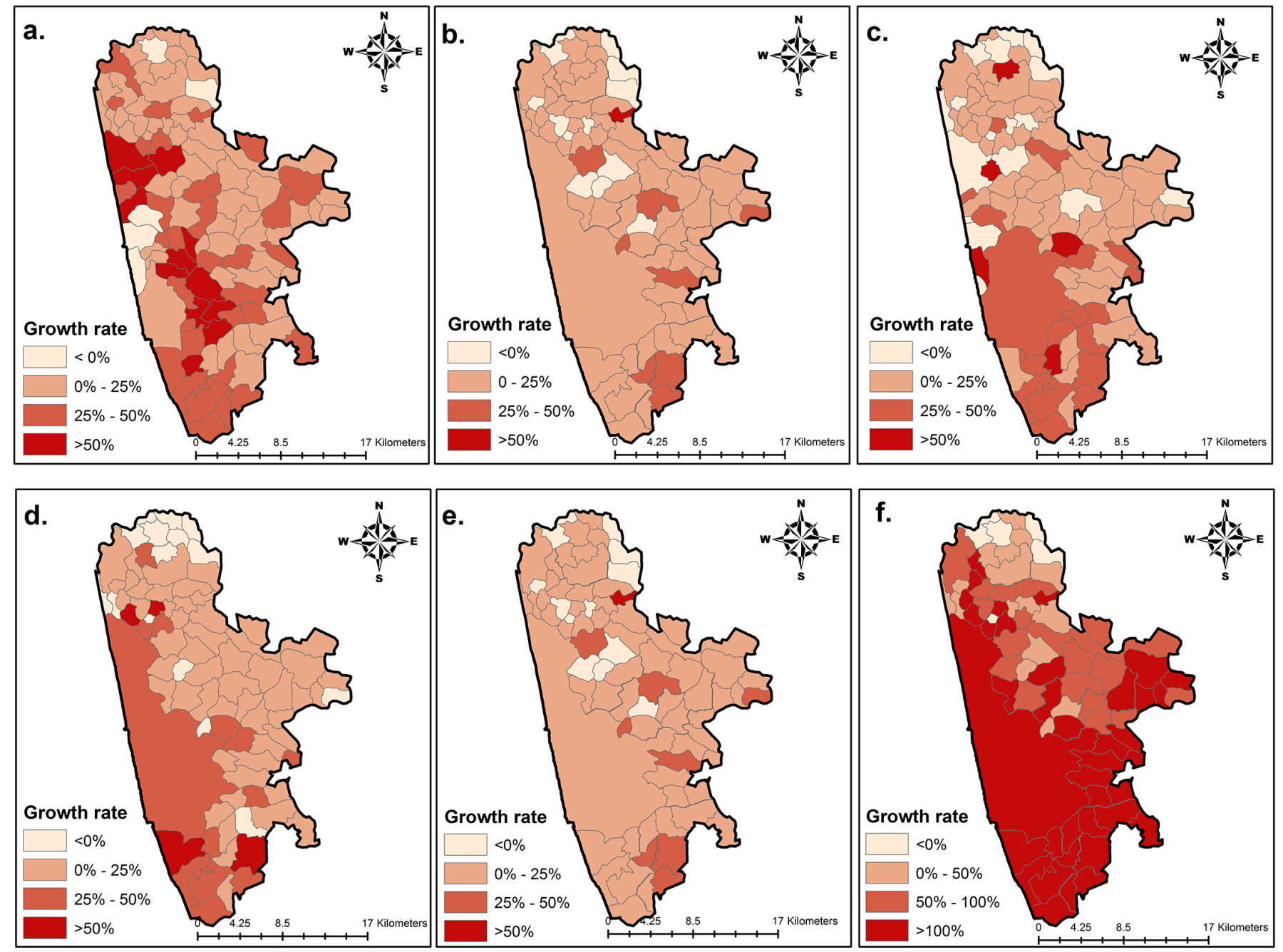

\section{Figure 5}

Growth rate of population in STs, CTs and villages of Mangalore taluk for a. 1961-71, b. 1971-81, c. 1981-91, d. 1991-2001, d. 2001-11 and f. 1961-2011

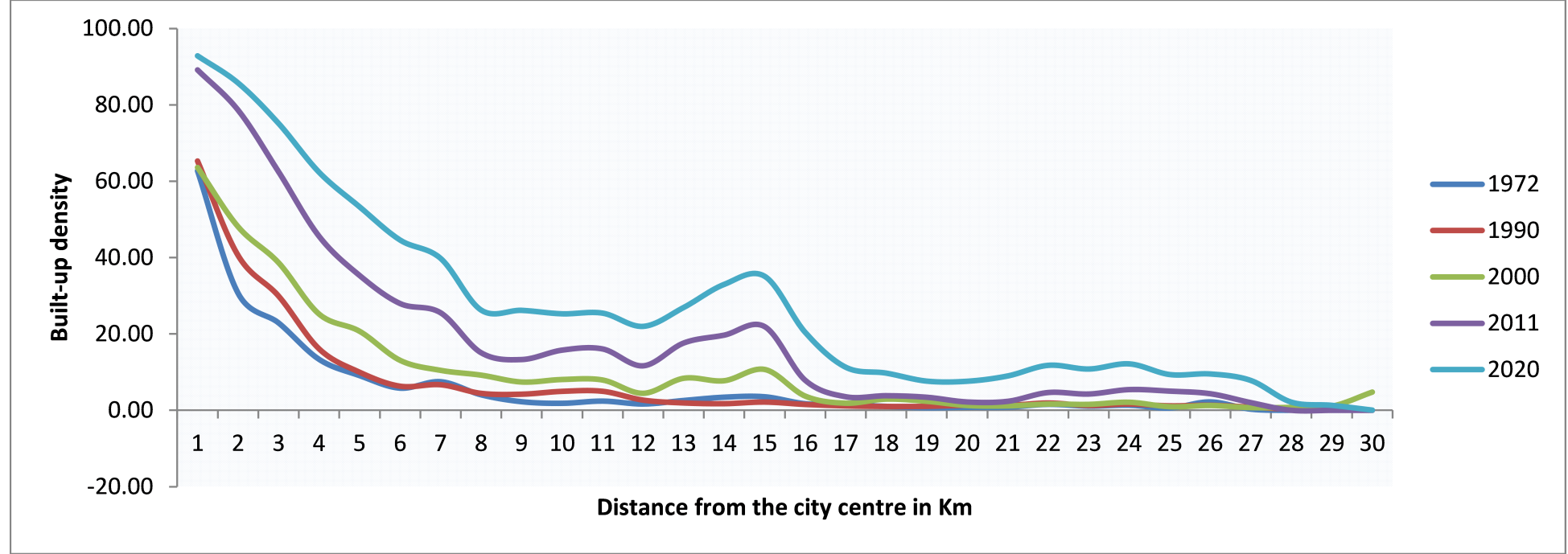


Figure 6

Horizontal spread of built-up density from the centre of the city during 1972, 1990, 2000, 2011 and 2020 in Mangaluru
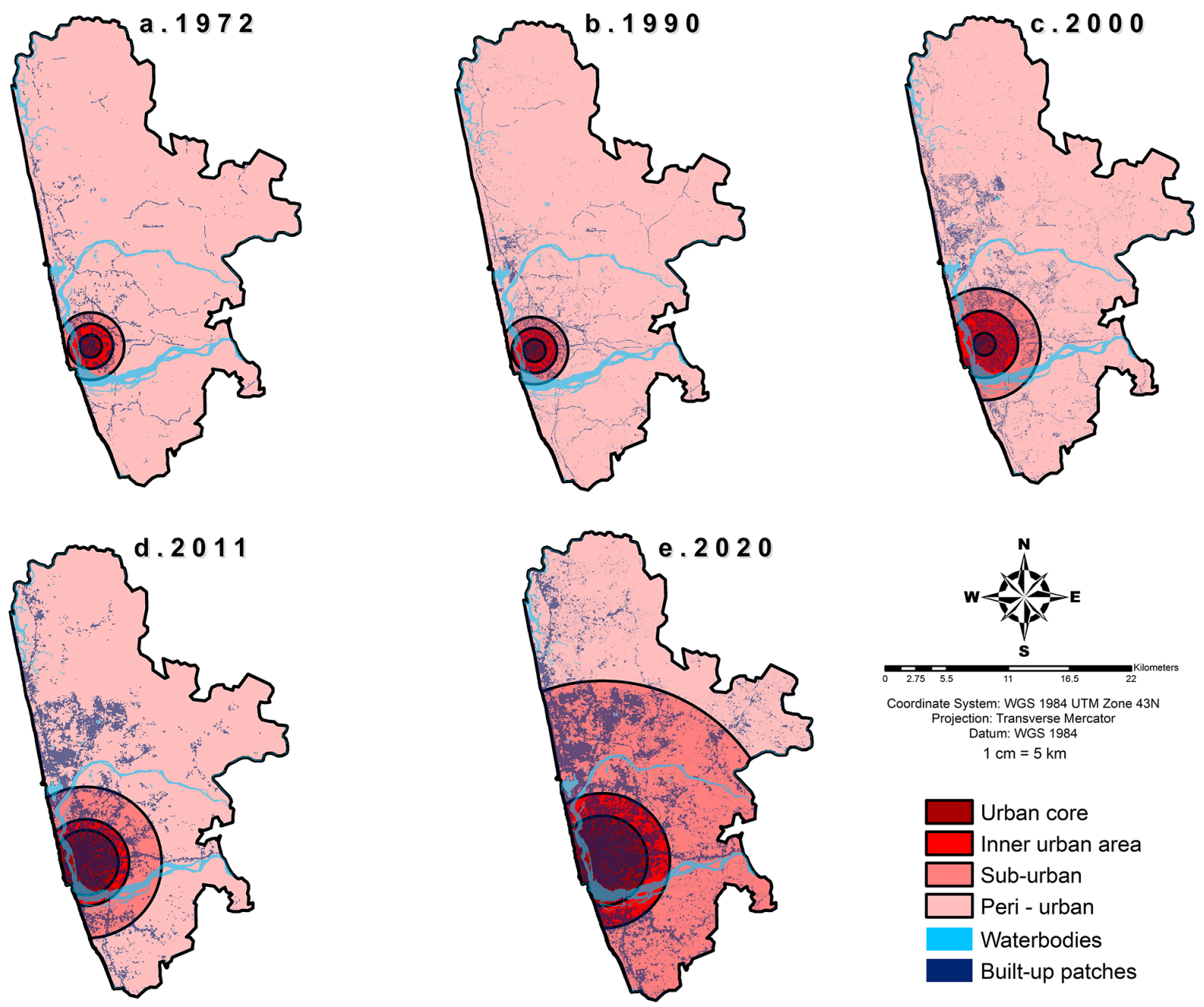

Figure 7

Urban form demarcation into the urban core, inner core, sub-urban and fringe or peri-urban based on density in Mangaluru 

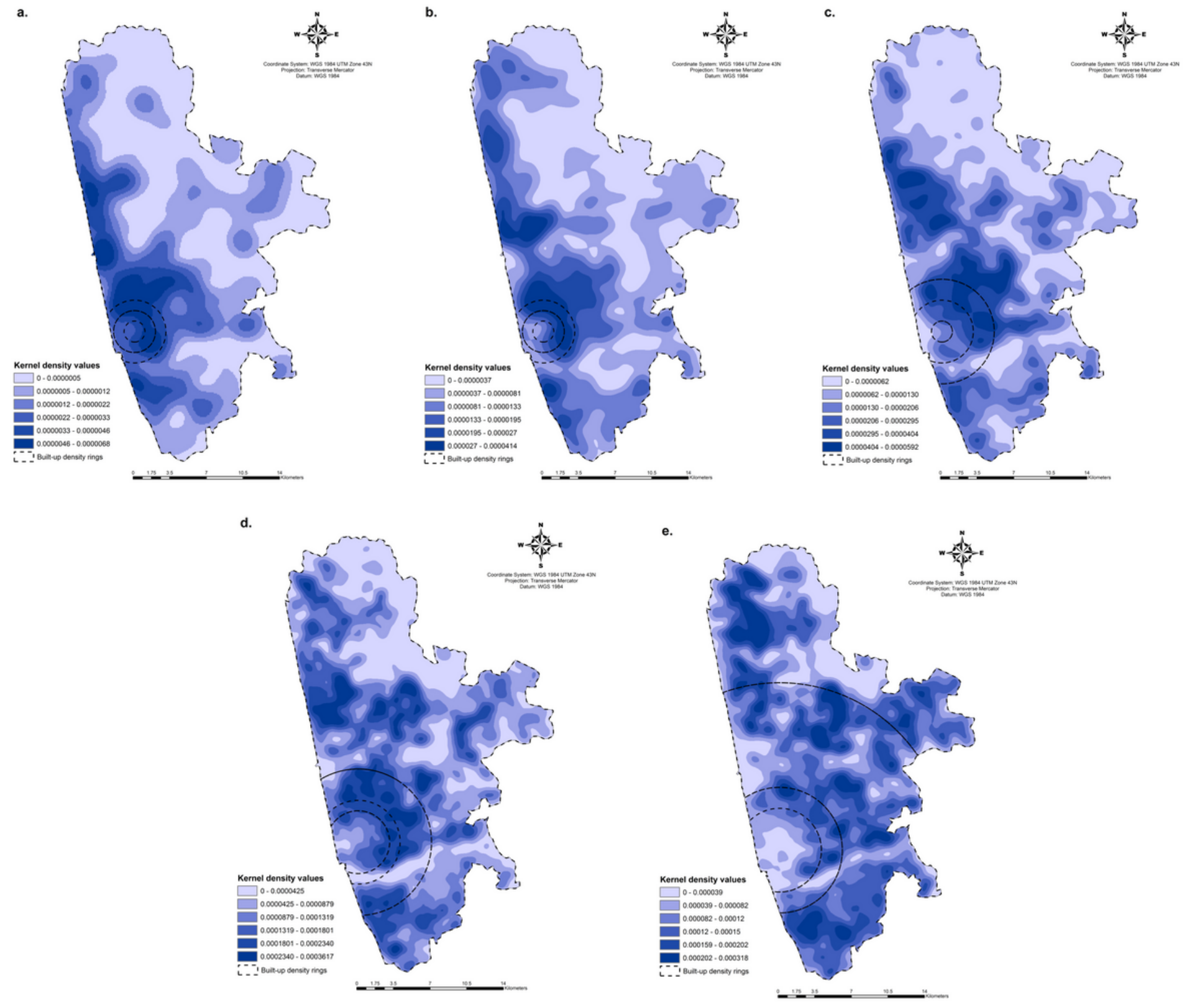

\section{Figure 8}

Kernel density variations of built-up patches of Mangaluru during a. 1972, b, 1990, c. 2000, d. 2011 and e. 2020 

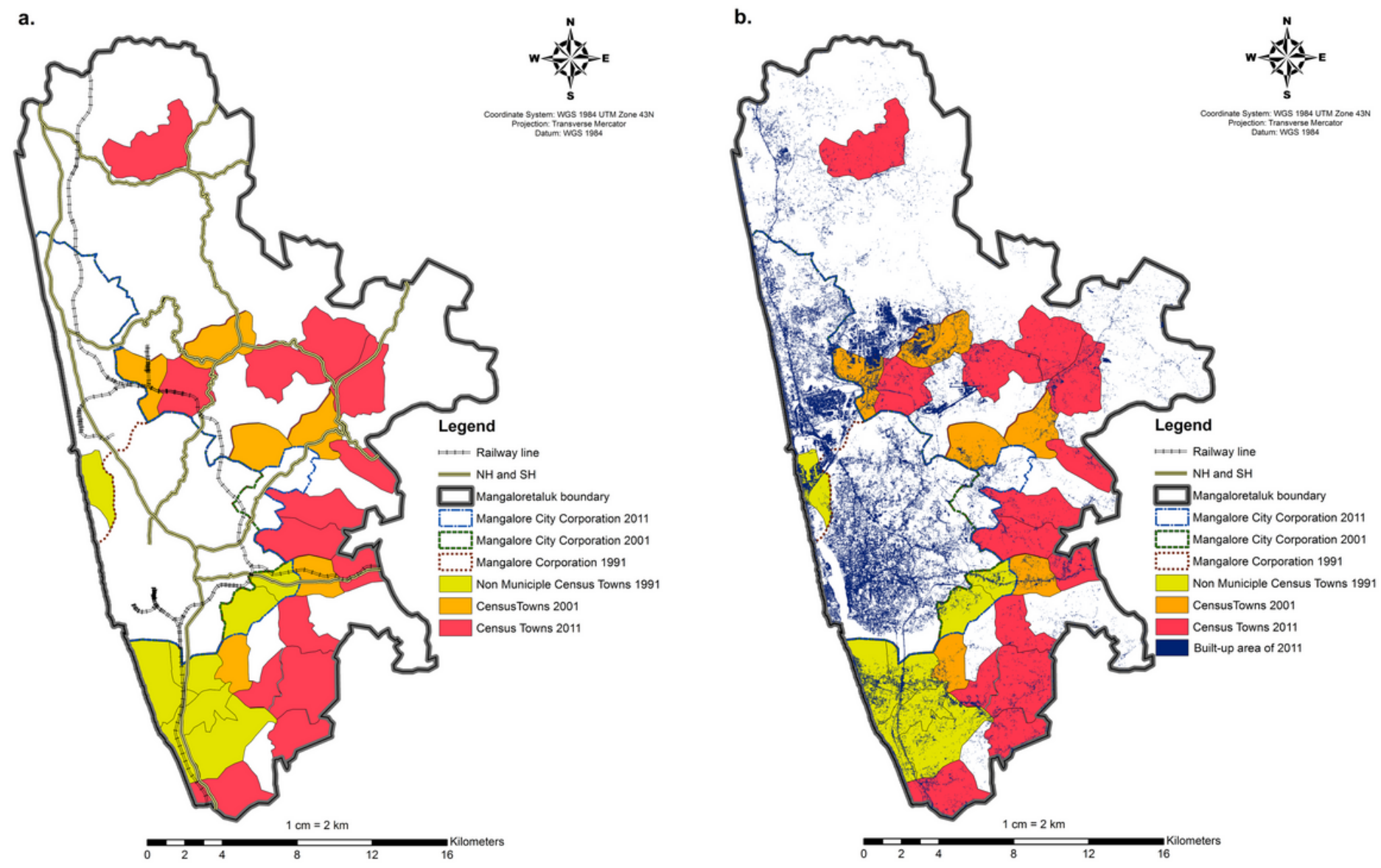

Figure 9

Shows distribution of CTs in Mangaluru in 1991, 2001 and 2011 with an overlay of a. transportation network and b. built-up area 